\title{
Calderón y los géneros dramáticos, con otras cuestiones anejas: honor, amor, legitimación política y autoridad de las taxonomías*
}

Calderón and dramatic genres with other related points: honour, love, political legitimacy and authority of taxonomies

\author{
IGNACIO ARELLANO AYUSO \\ GRISO. Departamento de Filología \\ Universidad de Navarra \\ Pamplona, 31009 \\ iarellano@unav.es \\ Orcid ID 0000-0002-3386-3668
}

Resumen: El artículo reflexiona sobre algunas cuestiones relacionadas con la taxonomía genérica de la obra calderoniana y comenta algunos ejemplos de obras concretas (especialmente No hay cosa como callar, de Calderón) en el marco de las convenciones de los diversos géneros trágicos o cómicos. Para un mejor entendimiento del teatro del Siglo de Oro y del inmenso Calderón, ha de plantearse la definición de un género como un camino de ida y vuelta, de conceptos estructurales a los análisis de las obras concretas, contrastando y corrigiendo detalles, convenciones funcionales y aspectos de la recepción. No pueden pasarse por alto las dificultades para establecer las taxonomías o sus límites, los modelos y la evolución de los mismos, planteadas por el enorme corpus del teatro aurisecular, y en particular el complejo corpus del teatro calderoniano.

Palabras clave: Géneros dramáticos. Calderón. Honor. Comedias.
RECIBIDO: 16 DE ENERO DE 2017 ACEPTADO: 18 DE ENERO DE 2017
Abstract: The article reflects on some aspects related to the generic taxonomy of the Calderonian theatre, and discusses some examples of particular plays (especially Calderón's No hay cosa como callar) within the framework of the conventions of the various tragic or comic genres. In order to achieve a better understanding of Golden Age theatre, and particularly of Calderon's work, the definition of genre has to be conceived of as a two-way road, correcting the structural concepts by means of analyses of particular plays, and taking into account funcional conventions as well as reception issues. The huge extension of the Golden Age theatre corpus and the complexity of Calderonian plays create difficulties that cannot be ignored about taxonomies and their limits, as well as about models and their evolution.

Keywords: Dramatic Genres. Calderón. Honour. Comedies.

* Este trabajo se enmarca el proyecto FFI2014-52007-P, "Autoridad y poder en el teatro del Siglo de Oro: estrategias, géneros, imágenes en la primera globalización", Ministerio de Economía y Competitividad, Gobierno de España. Dirección General de Investigación Científica y Técnica. Programa Estatal de Fomento de la Investigación Científica y Técnica de Excelencia. 
L

os géneros dramáticos del Siglo de Oro y su posible taxonomía vienen recibiendo cierta atención en los últimos años, y con razón, pues son de recepción de las obras y por tanto su comprensión e interpretación ${ }^{1}$. Al tema se dedica ahora un manojo de estudios en el volumen Calderón frente a los géneros dramáticos, recientemente editado por Antonio Sánchez Jiménez, volumen que me proporciona la oportunidad de retomar algunas cuestiones importantes que siguen, por lo que se ve, abiertas a la discusión.

Adelanto que no pretendo hacer una reseña crítica ni revisar sistemáticamente las páginas de esta colectánea, sino añadir algunos comentarios o precisiones provocados por la lectura de la citada publicación, que manejaré como catalizador de un debate abierto con implicaciones que considero -a menudo- fundamentales. Glosaré, por tanto, de manera irregular y libérrima, algunos de estos artículos, los que me parecen más provocadores -a menudo por no estar de acuerdo con sus conclusiones-, pero derivaré a veces hacia otros terrenos anejos, no tratados directamente por los estudiosos incluidos -y que no tenían, desde luego, obligación de tratar-.

EL GÉNERO COMO INSTRUMENTO, EL GÉNERO COMO PROBLEMA: ¿DOS ESCUELAS CRÍTICAS?

He tomado como epígrafe de este capitulillo el que Sánchez Jiménez adopta para su interesante pórtico-marco, en el que ya asoman un par de cuestiones merecedoras de algunas palabras. La consideración de instrumento parece en todo caso más adecuada para la noción de género que la de problema. Si el género constituye un problema es solo en el sentido de la dificultad para definir algunos de ellos, o establecer límites y precisar convenciones estructurantes en una fase de evolución creativa del fenómeno teatral -como es el Siglo de Oro-, o que implica una trayectoria larga y genéricamente múltiple, como es la de Calderón. Cierto -y a ello alude Sánchez Jiménez- que existen posturas críticas negadoras de los géneros y de la utilidad del concepto, pero no parecen posturas defendibles, pues la existencia de convenciones -que marcan horizontes de expectativas- es obvia y asoma en cada página de las preceptivas clásicas y auriseculares, sin contar con su puesta en escena en conjuntos de obras que sin duda constituyen modelos genéricos, aunque puedan percibirse

1. Ver, solo como ejemplo, Arellano 1999. 
grados diversos de cumplimiento o de evolución. No creo rentable entablar una disputa en este nivel de generalización negadora. Baste recordar que si en el mismo Siglo de Oro existe una marcada conciencia de las distinciones genéricas ${ }^{2}$ por alguna razón será y alguna importancia tendrán en cuanto a la conformación de las obras concretas.

Newels (151) señala, por ejemplo, que "alrededor de 1600 se observa [...] una nueva diferenciación del concepto global de comedia en los géneros de tragedia, comedia y tragicomedia". Suárez de Figueroa, en El pasajero (1617), distingue comedias "de cuerpo" y "de ingenio"; Salas Barbadillo en sus Coronas del Parnaso y platos de las Musas (1635), "comedias de tramoyas", "de capa y espada", "entremeses", "tragedias", "comedias de historia docta y grave", "comedias de alta y prodigiosa elocuencia", "autos sacramentales"; Pellicer de Tovar en su Idea de la comedia de Castilla (1639), comedias "heroicas", "de maraña amorosa", "trágicas" y "de mucho enredo"; el Padre Guerra en su famosa aprobación a la Verdadera Quinta Parte de Comedias de Calderón (1682) halla "comedias de santos, de historia y de amor, que llama el vulgo de capa y espada"; etc.

Dando, pues, por descontada la importancia de la noción genérica, lo que me interesa ahora es observar la descripción que ofrece Sánchez Jiménez en la parte principal de su prólogo, con algunas afirmaciones que pudieran resultar confusas y con implicaciones riesgosas para la interpretación y construcción del panorama crítico acerca de los géneros o de la misma recepción tout court del teatro áureo.

Distingue el estudioso dos escuelas, aquella de quienes emplean las categorías genéricas "para limitar o contrastar la intepretación de los textos" y aquella de quienes "proclaman su libertad hermenéutica por encima de las restricciones de una metodología que en su opinión resulta positivista" (7). Este planteamiento de "dos escuelas", la primera de las cuales correspondería a las filologías tradicionales cultivadas sobre todo en Europa, y la segunda, de propuestas más audaces, a la academia americana, me parece sumamente peligrosa. Por más que Sánchez Jiménez quiera despojar de connotaciones ${ }^{3}$ de

2. Esto no significa que los diferentes géneros estén claramente definidos o se perciban con límites rígidos, pero la conciencia de lo que llamamos 'género' es muy evidente y no se puede ignorar.

3. Sánchez Jiménez: "El grado de influencia del positivismo -y no pretendemos teñir el término de connotaciones de ningún tipo-..." (8). Pero el hecho mismo de tener que precisar que no pretende cargar de connotaciones el término está revelando la imposibilidad de tal propósito. Si no estuviera ya connotado, ¿por qué habría de hacerse semejante advertencia? 
cualquier tipo al término "positivismo" (8), no es posible. El término está ya, a estas alturas de la teoría literaria, completamente desprestigiado, y no corresponde además a la descripción que propone Sánchez Jiménez, sino que hace ya muchas décadas que se identifica con el acopio de datos y detalles secundarios y marginales poco útiles para acercarse al texto en sí. En realidad, cuando se menciona el término "positivismo" se piensa inmediatamente en el estadio de la teoría literaria de la segunda mitad del siglo XIX, que ya fue atacada por los formalistas rusos allá por $1915 \ldots$ De manera que calificar de positivista un método de acercamiento genérico a principios del siglo XXI es -quiérase o no- contaminarlo con un veneno letal. ${ }^{4}$ Pero es que además la perspectiva que se califica de "positivista" solo lo es en cuanto pretende un control racional, filológicamente responsable, de un texto. En este sentido cualquier escuela -adopte la perspectiva que quiera- debería fundarse en una mirada inicial y básica "positivista" como punto de partida, incluidas las aproximaciones "audaces" con las que se pretende caracterizar una de las mentadas escuelas.

Uno de los rasgos que servirían para establecer estas dos supuestas "escuelas" es la interpretación "política" (esto es, "moderna") de las obras ${ }^{5}$ frente al acercamiento "basado en premisas positivistas" o "tradicionales": "Los estudios más afines al positivismo han acudido a las categorías genéricas (tragedia y comedia con sus variaciones) para corregir interpretaciones a su parecer aberrantes dentro de ese marco" (8).

Ahora bien: se están mezclando en esas consideraciones aspectos muy diversos que conviene deslindar. Parecería que la escuela no positivista, avanzada, posmoderna, etc. se inclina a las interpretaciones políticas, mientras que la "positivista" acota "las supuestas referencias políticas esgrimiendo a menudo el argumento genérico" (8). Pero semejante camino es un camino

4. Significa además entrar en un juego perverso de contaminaciones conceptuales que opone a la escuela "tradicional" (obsoleta, arcaica, rancia y superada) y a la más actual, innovadora, audaz y abierta... (posmodernismo de variadas facetas) en una polaridad que en el fondo ataca -aunque no se quiera- a la misma raíz de las disciplinas humanísticas, abriendo vía libre a lo que no es más que un modelo de impresionismo y divagación metafórica que a menudo irrespeta al texto.

5. Se entiende que esta interpretación política corresponde a posturas de denuncia y hasta "subversivas", en el polo opuesto a Maravall. En su resumen de las aportaciones del volumen, a propósito de la de Folger, vuelve a insistir Sánchez Jiménez en la posibilidad de plantear lecturas políticas más o menos ocultas en las obras calderonianas, y "la relación de esta posibilidad con el género de las piezas" (12). Pero la interpretación política de una pieza no depende del género, sino de diversos componentes y su relación con las circunstancias históricas y políticas supuestamente reflejadas en la obra: esta relación debe ser fundada en datos textuales, no atribuida apriorísticamente a género alguno. 
cerrado; de hecho, no se produce en la crítica tan a menudo como sugiere Sánchez Jiménez -y desde luego este rasgo de la lectura política no puede diferenciar dos "escuelas" -. En otras palabras: una lectura política inventada, fantástica, poco justificada o incluso contradictoria con los datos textuales no puede caracterizar ninguna escuela crítica; solo caracteriza una incompetencia lectora. La pertinencia de una interpretación política no depende de la perspectiva "positivista" o "avanzada" de un teórico-crítico, sino de los fundamentos y coherencia textuales. La posibilidad de proponer lecturas políticas nunca puede corresponder a una perspectiva teórica general, sino que depende de las obras concretas: habrá piezas con elementos de crítica político-social y otras completamente ajenas a esas preocupaciones, y habrá piezas de defensa política del sistema y otras que critiquen, si no el sistema en sí, aspectos y circunstancias, con mayor o menor agresividad.

Tanto una como otra (la lectura maravalliana propagandística o la "subversiva") son posturas falsas si se entienden como estrategias generales del teatro áureo. En el teatro del Siglo de Oro hay piezas exaltadoras y hay denuncia. La tarea es examinar las obras concretas y su sentido concreto. Que Calderón incluya motivos críticos no significa que sea subversivo; que defienda el sistema no significa que no pueda ser crítico. Es posible incluso que la defensa del sistema resulte subversiva en la práctica (como pasó con la Política de Dios de Quevedo según algunos de sus receptores). Las interpretaciones monolíticas -se asienten en conceptos genéricos o no- son incapaces de dar cuenta de la complejidad del corpus dramático áureo. En todo caso, la oposición de perspectivas no debería hacerse entre "posivista" e "innovadora", sino entre:

1) intérpretes monolíticos, que ven en el teatro una máquina de propaganda ideológica, bien a favor (Maravall) o en contra (numerosos estudiosos, algunos mencionados en el presente volumen); e

2) intérpretes que abogan por valoraciones fundamentadas de cada pieza, que tengan en cuenta convenciones, contextos y sentidos apoyadas en meticulosas lecturas filológicas (y en el sentido común).

El crítico llamado aquí "positivista” -y que sería preferible calificar de filológicamente competente- no se negará a ninguna clase de interpretación ni optará por ninguna a priori, sino que pretenderá controlar esa lectura $-\mathrm{O}$ cualquiera- a partir de la comprensión básica del texto. Así que son muy po- 
sibles las lecturas políticas (en cualquier sentido que el texto imponga) en una escuela "positivista" bien entendida, que solo negará aquellas que resulten infundadas o incoherentes, por impresionistas o por ignorar el texto.

En ese terreno el género no es tan relevante como apunta Sánchez Jiménez, ya que cualquier obra de cualquier género puede tener lecturas de este tipo. Lo único que cabe decir es que la tragedia suele inclinarse hacia la crítica, y la comedia hacia el elogio cortesano; que es inverosímil que las fiestas palaciegas de gran espectáculo constituyan aceradas críticas al poder -sin perjuicio de integrar consejos de buen gobierno o críticas diversas según los casos-, y que la comedia burlesca difícilmente puede reflejar a los monarcas verdaderos que podían divertirse con los muñecos carnavalescos de las parodias, pero no verse representados críticamente en ellos...

Quizá algunos ejemplos puedan ayudar a comprender este asunto, ya que, si el género no parece esencial en este terreno, sí parece importante -y peligrosa- la bifurcación de propuestas lectoras en torno a la cuestión de la crítica social y política, y conviene apuntar algunos comentarios. Aduciré solo tres casos significativos.

LECTURAS POLÍTICAS Y EL PRURITO INNOVADOR. CASOS EJEMPLARES: Quevedo, Calderón, Bances Candamo

Podemos empezar por una comedia cuyo género o especie dramática no parece ofrecer dificultades, al menos en su objetivo último. ${ }^{6}$ Cómo ha de ser el privado, única comedia conservada de Quevedo, constituye para una mirada ingenua un caso de teatro cortesano, dirigido a espectadores áulicos, caracterizado por una serie de claves y homologías alusivas a circunstancias coetáneas. ${ }^{7}$ El título del valido protagonista, marqués de Valisero, es anagrama de Olivares; su tío el duque de Sartabal -anagrama de Baltasar-, corresponde a Baltasar de Zúñiga, tío de Olivares, que compartió la privanza con su sobrino, etc.

Se trata, en suma, de una pieza de propaganda política, que tiene por objeto la exaltación del valido perfecto encarnado por Olivares en la vida real.

6. Dejo aparte por el momento la definición estructural de una comedia como esta y me ocupo solo de la vertiente política en relación con su género/ horizonte de emisión y recepción. Uso en este pasaje fragmentos de la introducción a la obra en Quevedo 2011.

7. Remito a las notas puestas en la citada edición para este tejido de alusiones que ahora no me detengo a precisar. 
Sin embargo, en la crítica reciente aparecen lecturas que buscan una mayor originalidad, amén de "salvar" a la comedia de acusaciones -ya antiguaspor lo que consideraban su desmedida adulación al privado. Y así Frederick de Armas sostiene que la obra no es un mero ejercicio de alabanza -con lo que se puede estar de acuerdo-, y sugiere toda una serie de críticas contra el nuevo monarca -con lo que no hay más remedio que discrepar-: "Una lectura detenida muestra cuatro áreas problemáticas en la presentación de Fernando/Felipe IV: su crueldad, su afeminamiento, su homoerotismo y su donjuanismo" (2004, 10-11).

Sin embargo, ninguna de esas áreas puede demostrarse con el texto de Quevedo. La crueldad se exhibiría en la adopción del sobrenombre de Justiciero (compartido con don Pedro el Cruel, por otros llamado fusticiero) y en la alusión a la muerte de don Rodrigo Calderón (v. 116) al asegurar el rey que hará justicia de los malos ministros. Pero la comedia desmiente la crueldad de don Pedro, que en todo caso es alusión marginal. La más importante cuestión de la justicia cumplida con don Rodrigo está mal interpretada por De Armas. Corresponde exactamente al deber de un buen rey, como aclara meridianamente el mismo Quevedo en Mundo caduco:

Y conociose aquí cuánto más peligrosa es en los reyes la clemencia con los traidores que sus armas y sus odios, pues el ánimo vil se alienta con la piedad que desprecia, y se desmaya con el castigo que huye; y aquel rey es tirano contra sí que perdona al que desprecia su bondad. $(2000,96)$

Que don Rodrigo Calderón se comportase heroicamente en la hora de la muerte no le hace merecedor de indulto ni constituye al rey en juez cruel, sino que convierte al reo en ejemplo de caída de privados y de valor en la hora definitiva, una vez aceptada la lección de su castigo. El mismo Quevedo en Grandes anales de quince días escribe sobre esto:

Muchas vidas y muchas honras ha puesto en salvo con esta cabeza su majestad, [...] toda España debe en este castigo la satisfacción de muchas quejas, y la medicina de grandes dolencias, y un temor que irá a la mano a las demasías de los ambiciosos; y deberá el mundo a su majestad el haber hecho del mayor escándalo el mayor ejemplo. $(2005,210)$ 
No hacen falta mayores comentarios para entender qué piensa Quevedo del ajusticiamiento de don Rodrigo Calderón.

La dependencia sexual del rey se mostraría a través de los temas de la feminidad y homoerotismo, según De Armas, quien aduce que el nuevo rey se identifica con la imagen de la aurora ('femenina'). Pero si se lee con cuidado el texto se advierte que lo que realmente hay es una sencilla alegoría de dos metáforas: el rey muerto es el sol que se ha puesto y el rey nuevo la aurora que surge, sin ninguna implicación sexual en el motivo. Igualmente injustificado es suponer homoerotismo en la imagen masculina de Atlas para Olivares, en quien se apoyaría el afeminado rey, imagen absolutamente lexicalizada en la iconografía olivariana. ${ }^{8}$

$\mathrm{Y}$ en cuanto al donjuanismo bien podía existir en la actividad cotidiana del rey, pero no se le acusa de ello en la comedia.

Otro componente crítico contra el rey y el valido lo ve Iglesias (271) en el hecho -algo paradójico- de que al defender a Olivares de una serie de acusaciones, denuncia los principales problemas que tenía España, sin olvidar además las discrepancias entre elogio y realidad. Pero no se puede defender a alguien sin negar las acusaciones y el elogio, por su propia esencia tiende a exagerar, negar, aumentar y orientar la realidad según el propósito de la alabanza. Según el razonamiento de Iglesias no podría existir el elogio, pues la inevitable ponderación panegírica resultaría siempre una denuncia.

Por lo demás, parece abusivo entender como crítica una obra situada en el principio del reinado. Quevedo era hombre de poca paciencia, pero empezar a negar ya en 1621 las capacidades del rey y del valido parece excesivo hasta para don Francisco. Escribe Iglesias:

Teniendo en cuenta, por lo tanto, la forma ambigua en que se nos presenta la figura del conde duque en esta comedia, no parece acertado seguir manteniendo, sin ningún tipo de matización, como con frecuencia se ha hecho, que Cómo ba de ser el privado solo persigue de forma servil la defensa de Olivares y de su estrategia política [...]. Esta comedia en

8. Es absolutamente inverosímil que Quevedo sugiriese ninguna relación homoerótica entre Felipe IV y Olivares. De hecho no la sugiere en ningún momento. Las imágenes de Atlante o de Hércules para los privados y en particular para Olivares se hacen tópicas y expresan su función de soporte del rey, pero no implican -sus contextos no lo autorizan- rasgos sexuales. Rico Ferrer traza un laberinto de feminizaciones y masculinismos en crisis con el triángulo QuevedoFelipe IV-Olivares, decididamente grotesco con absoluto descontrol e ignorancia de los textos, según se comenta en Arellano 2015b. 
concreto muestra muchas más críticas sobre Olivares y Felipe IV que buena parte de las obras del periodo entre principios de 1621 y 1629. $(289,295)^{9}$

Todo esto es rizar el rizo. Cómo ha de ser el privado es, sin duda, una pieza más de las incitadas por el propio Olivares, directa o indirectamente, o bien surgidas de la propia iniciativa del poeta, para agradar al poder y manifestar también un ideal de político en momentos de crisis y cambios, proyectando una imagen positiva del monarca y su valido en el comienzo de un reinado que abre nuevas perspectivas. Después, la opinión de Quevedo sobre Olivares cambiará radicalmente.

Calderón constituye otra modalidad de poeta áulico, como dramaturgo de corte. Tradicionalmente visto como defensor de un sistema reaccionario por críticos prejuiciados y poco leídos, representa un buen caso de complejidad. No merece la pena detenerse en el evidente aspecto de la mitificación y legitimación del rey y de la Casa de Austria en los autos y loas calderonianos, que ha estudiado con tanta competencia Enrique Rull (1983; 1985), pero resulta significativo que en una pieza como El nuevo palacio del Retiro, auto sacramental celebrativo de la construcción del nuevo palacio del rey, ${ }^{10}$ incluya una dura crítica a la postura de Olivares frente a los comerciantes y financieros marranos. ${ }^{11}$

Aparte de otras referencias a los conflictos de poder en el escenario de la corte, en este auto que Paterson ha calificado de "palimpsesto político" se puede leer un rechazo a controvertidas posturas de Olivares: en la versión autosacramental de las consultas habituales de los viernes (vv. 870-1022) el Judaísmo presenta un memorial pidiendo libertad de tráfico comercial, solicitud que el rey manda romper, expulsando a los judíos, los únicos solicitantes rechazados por el rey:

9. Si tenemos en cuenta que Felipe IV sube al trono el 21 de marzo de 1621 parece demasiado suponer que a "principios de 1621 " arreciaban críticas contra el monarca y su privado, el cual sube formalmente al valimiento en 1622 .

10. Montaner Frutos (397) apunta que quizá parezca raro buscar estos aspectos políticos en el género sacramental, pero en realidad es perfectamente explicable si se tiene en cuenta la doble dimensión de los autos, la alegórica y la historial. Pues el género del auto, que ha sido a menudo visto como atemporal, fuera de la historia, colocado en el territorio de la "eternidad", es precisamente uno de los más implicados -desde su vertiente historial- en cuestiones "políticas". Ver Arellano 2001.

11. Para lo que sigue tomo materiales de Arellano 2011a. Para este auto y sus circunstancias, ver la edición de Paterson. 


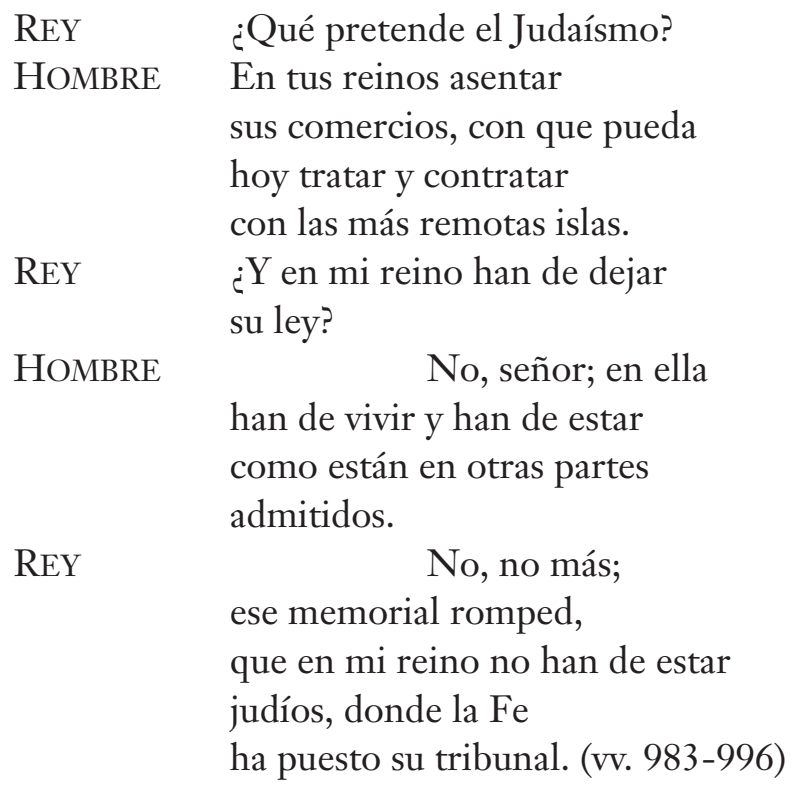

Pocas dudas puede haber de que la escena alude a la polémica desatada en torno a los asentistas y financieros conversos apoyados por Olivares, y el de los incidentes antisemitas de la década de los treinta (1632, incidente del Cristo flagelado por los criptojudíos de Madrid, según declaraciones que a la Inquisición hicieron varios niños, lo que acabó en un auto de fe; 1636, auto de fe contra judaizantes...). Ingenua me parece la interpretación de Pulido Serrano, quien ve en El nuevo palacio del Retiro una defensa de Olivares:

Pensamos que el verdadero objetivo de Calderón es defender al Conde Duque de los ataques que sufría por parte de todos aquellos quienes le acusaban de ser protector de los judíos y de querer traerles a vivir a España [...]. El argumento de este auto se convierte en una declaración pública por parte de Olivares para intentar liberarse de la sospecha de filojudaísmo que sobre él caía [...]; el público, la corte de Madrid, podía ver cómo el Conde Duque de Olivares trataba con rudo desdén y evidente desprecio al judaísmo. (202)

No obstante, el rechazo de los judíos en la consulta proviene directamente del rey, cuya conducta en El nuevo palacio solo puede interpretarse como desautorización de la política del valido en este asunto. 
Es evidente la exaltación monárquica (Felipe IV se asimila nada menos que a Cristo) y el elogio parcial al valido (imagen y semejanza del rey, como el Hombre es imagen y semejanza de Dios) en muchos pasajes de El nuevo palacio, pero por muy poeta cortesano que fuera Calderón no siempre se atiene a la "diplomacia" ni evita las "impertinencias" ni los enfrentamientos con poderosos cuyas posturas no comparte.

En la breve descripción de los ejemplos anteriores asoma una tendencia que me parece perversa -y que podría ejemplificarse con muchos otros ejemplos-: esto es, interpretar los elogios como críticas y las críticas como elogios por prurito de originalidad, no por coherencia interna y externa de los textos.

Caso particularmente interesante en este sentido es el de Bances Candamo, sucesor de Calderón como dramaturgo de corte. El corpus de Bances sí refleja en su organización genérica los propósitos de su teatro, confirmados en su obra teórica Teatro de los teatros. No voy a entrar en la consideración sistemática de su teoría y práctica teatral, ${ }^{12}$ y me limitaré a señalar algunas cuestiones acerca de los componentes políticos en sus comedias y en los géneros de las mismas.

La reducción homogénea del público -estrictamente cortesano- explica la ausencia de ciertos géneros (como el de capa y espada) y el dominio de las comedias historiales y de fábrica. Todas las variedades de sus obras (comedias de fábrica, historiales, fábulas...) tienen por principal objetivo distraer los ocios del rey añadiendo siempre el componente pedagógico, educativo, sobre el arte del buen gobierno y las virtudes del gobernante o caballero. ${ }^{13} \mathrm{La}$ función panegírica, la más obvia, ha sido discutida por quienes han visto en las obras de Bances una crítica sistemática al monarca y a las circunstancias de la corte, a partir de la interpretación que propuso en su edición del Teatro de los teatros Duncan Moir.

Moir atribuye importancia capital a un pasaje famoso en el que Bances habla de la tarea del dramaturgo como de un "decir sin decir":

Son las comedias de los reyes unas historias vivas que, sin hablar con ellos, les han de instruir con tal respecto que sea su misma razón quien de lo que ve tome las advertencias, y no el ingenio quien se las diga. Para este decir sin decir ¿quién dudará que sea menester gran arte? (Bances 57)

12. Sobre estas cuestiones en Bances remito solo a Arellano 1988a, 1988b, 1998.

13. Como afirma en el Teatro de los teatros: "Ni aun en la diversión se han de apartar del bien público los monarcas, porque han de descansar de obrar aprendiendo a obrar" (57). 
que Moir glosa:

Es pasaje de singular interés y de importancia internacional. Que yo sepa es el único documento en el que un dramaturgo europeo del siglo XVII confiesa abiertamente que escribe obras palaciegas con intención política... es documento clave para la comprensión de las comedias y zarzuelas palaciegas de Bances y de los fines para los cuales se compusieron. (xcv)

El alcance que da Moir a esta actitud política de Bances queda más claro en otros lugares, donde comenta las "atrevidas alusiones políticas" (xxx), la "índole peligrosa" de algunas comedias (xxxi), etc. Tras Moir, muchos trabajos modernos (Díaz Castañón, Moli Frigola, Quintero...) dedicados al dramaturgo aprecian estos mismos rasgos ${ }^{14}$ de compromiso político y denuncia, a pesar de que ese "decir sin decir" no es una confesión de astucia ni una declaración de intenciones políticas especiales, como creen los mencionados estudiosos, sino todo lo contrario: se trata en realidad de una restricción de la crudeza con que el dramaturgo podría presentar sus lecciones, una exigencia del respeto debido al monarca, sin particular originalidad. ${ }^{15}$ Saavedra Fajardo, por ejemplo, dedica varias páginas al mismo asunto en la empresa XLVIII con expresiones muy cercanas a la de Bances:

No pueden sufrir los príncipes [...] superioridad, pareciéndoles que les pierde el respeto quien les habla claramente [...]; lastimar con las verdades [...] más es malicia que celo [...]. Aun Dios las manifestó con recato a los príncipes [...] por sueños [...], no claramente, sino en figuras y jeroglíficos [...]. Conténtese el ministro con que las llegue a conocer el príncipe, y si pudiere por señas no use palabras [...]. Todas se pueden decir si se saben decir... $(572,575)$

Otro pasaje clave para las lecturas "subversivas" de Bances es la alusión a Alejandro, que

no consintió que fuesen tratadas sus perfecciones (y entre ellas su defecto) de otros colores que los de Apeles, y con razón, porque se han de

14. Remito para esta discusión a Arellano, trabajos citados en la bibliografía final.

15. Para el tratamiento de esta cuestión en la teoría política, ver Galván 2009, 52-59. 
retratar los príncipes adonde ellos se han de mirar de suerte que ni las perfecciones les desvanezcan en la adulación ni los defectos en la reprensión les ofendan. (58)

Texto que fue mal entendido por Moir $(73)^{16}$ y que confirma la interpretación que propongo para el decir sin decir. El mismo caso utiliza Calderón en Darlo todo y no dar nada, donde el rey ha encargado su retrato a tres pintores. Timantes lo falsea, eludiendo el defecto de Alejandro (tuerto) pintando los dos ojos sanos; Zeuxis pinta verazmente el ojo tuerto, ofendiendo el decoro real; Apeles hace un retrato de perfil, dejando oculto el lado defectuoso:

\begin{tabular}{|c|c|}
\hline EJANDRO & $\begin{array}{l}\text {... Solo vos sabéis cómo } \\
\text { se ha de hablar a su rey, puesto } \\
\text { que a medio perfil está } \\
\text { parecido con extremo, } \\
\text { con que la falta ni dicha } \\
\text { ni callada queda } \\
{[\ldots]} \\
\text { Y para que quede al mundo } \\
\text { este político ejemplo, } \\
\text { de que ha de buscarse modo } \\
\text { de hablar a un rey con tal tiento } \\
\text { que ni disuene la voz } \\
\text { ni lisonjee el silencio, } \\
\text { nadie sino Apeles pueda } \\
\text { retratarme desde hov... (1987b, } 1028\end{array}$ \\
\hline
\end{tabular}

Dejaré aquí este asunto: me parece claro que las dimensiones políticas (críticas o panegíricas) pueden darse o no en numerosas obras. La precisión de su alcance puede resultar explicada o justificada por aspectos genéricos, pero el género no sirve como guía de lectura global para decidir unas implicaciones políticas supuestamente ‘de oposición al régimen' y ocultas sistemáticamente en el teatro aurisecular.

16. Cree que el defecto es la ira y que la fuente es Erasmo. Creo que el pasaje calderoniano que comento acto seguido es suficientemente aclaratorio del motivo a que realmente se refiere Bances, el problema de pintar al rey sin reflejar su ojo tuerto. 
En Calderón frente a los géneros dramáticos, la contribución de De Armas, titulada "Calderón y Virgilio: El golfo de las sirenas como égloga", retoma, aunque en esta ocasión de manera marginal, el asunto de los significados políticos de las obras calderonianas en su análisis de paralelismos simbólicos de la zarzuela calderoniana y las Bucólicas de Virgilio.

Los problemas no afectan solo a este tipo de lecturas, claro está. A cada paso puede surgir, en el mar de la comedia nueva, una isla de límites poco nítidos.

\section{NO HAY COSA COMO CALLAR, CASO LÍMITE Y DE GÉNERO PROBLEMÁTICO}

Una de las piezas más enigmáticas para los estudiosos en cuanto a su adscripción genérica -a juzgar por las divergencias en su análisis- es No bay cosa como callar, a la que el maestro tolosano y calderonista universal, Marc Vitse, dedica sus reflexiones, cuya agudeza y elaborada argumentación constituyen una lujosa trampa para el lector, que ante su admirable despliegue estilístico puede quedar elevado sin percibir la radical desviación de algunos motivos clave para comprender la delimitación genérica y el sentido mismo de la obra. Quandoque bonus dormitat Homerus, según intentaré mostrar entablando diálogo -quizá icareo- con Vitse y su "No bay cosa como callar, pieza límite" (27-43).

Pieza límite porque -según Vitse- desactiva los elementos trágicos para conformar una peculiar comedia que incluye una violación brutal con final feliz (de una felicidad, como se verá, algo peculiar también).

La cuestión principal es decidir si se trata de una comedia de capa y espada, de índole más bien -moderadamente- ludico-cómica, o una pieza seria, drama o tragedia. ${ }^{17}$

En la trama, don Juan de Mendoza, un galán cínico y despreocupado que tiene como "dama fija" a Marcela -a la que engaña y olvida cuando quiere- ${ }^{18}$ se prenda de Leonor, que mantiene unas honestas relaciones con don Luis. En un incendio que le obliga a abandonar su casa, Leonor es acogida por su vecino don Pedro, padre de don Juan. Este, que regresa a su cuarto para reco-

17. Arellano 2013, para la bibliografía y breve historia de la recepción de esta pieza.

18. "Marcela / es dama de cada día; / ni entra ni sale en la cuenta. / Todo ocioso cortesano / dice un adagio que tenga / una dama de respeto / que sin estorbar divierta..." (Calderón 1987a, 1002). No se ve la "perfecta concordancia con el código de amor verdadero" que advierte Vitse (30) en la conducta de don Juan. Menos aun en su comportamiento con Leonor como intentaré mostrar. 
ger unos papeles que necesita en su viaje a Fuenterrabía (donde va a participar en la liberación de la ciudad, sitiada por los franceses), la sorprende y la viola, huyendo acto seguido y dejando en manos de su víctima una venera con un retrato de Marcela.

Durante dos meses Leonor sufre en silencio su desgracia. Un día el coche de Marcela vuelca y la dama es socorrida en casa de Leonor, que reconoce a la mujer del retrato. Leonor averigua la casa de Marcela, donde acude tapada a indagar la identidad de su ofensor, pero se ve obligada por la presencia de don Diego (hermano de Leonor y enamorado de Marcela desde el día del accidente del coche) a desprenderse de la venera y salir corriendo sin lograr su objetivo.

Don Juan y don Luis regresan de Fuenterrabía. En el camino don Juan cuenta a su amigo la aventura de la violación, pero desconoce la identidad de la mujer. Leonor rompe sus relaciones con don Luis, que ignora la causa de esta ruptura y de la tristeza de la dama. Marcela, para provocar los celos de don Juan regala la venera a don Diego, con lo cual este objeto regresa a casa de Leonor, quien vuelve a apoderarse del retrato. Por fin, en una riña de celos que estalla en casa de Marcela, don Juan hiere a un hombre y se refugia casualmente en la casa de Leonor: en ese momento se reconocen los dos. Leonor sugiere al galán que repare el deshonor, casándose con ella o al menos guardando el secreto mientras ella se recluye en un convento. Don Juan rechaza el matrimonio, pero llegan a la casa don Diego y don Luis, que sorprenden a don Juan discutiendo con Leonor en términos enigmáticos alusivos al honor. Acude el viejo don Pedro, protector de Leonor, y ante la complicada situación don Juan acepta casarse, sin dar más explicaciones a nadie, aunque don Luis comprende claramente que Leonor es la mujer violada del anterior relato de don Juan y los demás algo deben de intuir.

En el citado trabajo anterior he defendido las dimensiones trágicas de esta obra; Vitse niega mis conclusiones apoyado en varios argumentos fundamentales -que enseguida discutiré-, pero no justifica la supuesta impertinencia de mis propios argumentos.

Las bases que permitirían una consideración cómica -o al menos "feliz"- de la obra serían la condición de don Juan de galán "redimible" -por fiel observante del código caballeresco- y la calidad de heroína admirable de Leonor, que conduciría a un final triunfante y, por tanto, feliz, característico de la comedia. 


\section{¿DON JUAN, GALÁN REDIMIBLE?}

Resulta sospechoso que el erudito que pretende redimir a don Juan utilice tales términos para describirlo a él y a su conducta que hacen muy complicada tal redención: violador, cínico violador, insoportable crimen, estupro, insufrible inverecundia, odiosísimo crimen, abominable y deshonesto abuso... Es posible que después de tal batería a Vitse aún le parezca el galán redimible por sus "micropositividades" (32), pero no resulta precisamente un modelo de caballeros.

Don Juan, en efecto, no observa el código caballeresco, o al menos sus cumplimientos parciales del código son poco significativos. Va a la guerra, sí, pero no respeta a Marcela ni menos a Leonor. Es un violador cínico y no arrepentido, negándose al matrimonio que solo aceptará ante insuperables complicaciones. No creo que los argumentos de Vitse puedan exculparlo: me parece un excesivo retorcimiento valorar su negativa a casarse con quien él piensa que es "una mujercilla" como expresión de su respeto al código del honor. Escribe Vitse:

Lo que nos dice el violentador es que él [...] nunca aceptará casarse con una mujer sin honor. Con ello no solamente previene cualquier eventual reclamación de parte de la para él mujercilla a la que acaba de gozar [...], también reafirma la ley de los celos de honor que quiere que para todo caballero de la sociedad dramática calderoniana es impensable e inaceptable el casamiento con una dama objeto de la más leve sospecha contra su honor. (31)

En esas líneas se olvida que es don Juan precisamente el que ha deshecho el honor de la dama violada. Y además ¿por qué se atribuye a don Juan el pensamiento de que Leonor es una mujercilla? ${ }^{19}$ En la escena clave, Leonor -con un discurso cuya calidad lingüística evidencia en sí misma su calidad social- le

19. Vitse vuelve al argumento: don Juan "no tiene hasta ahora la información suficiente para dejar de pensar que la mujer que halló casualmente en su aposento no podía ser otra cosa que una mujercilla" (40). Creo que tiene suficiente información para saber que es una dama; recuérdese el inequívoco diálogo aducido del momento de la violación que cito enseguida. Y aunque fuera una mujercilla, ¿la violación es cosa menor? Violar a una dama deshonrándola, y luego negarse a la boda porque es una mujer deshonrada no parece precisamente responder al código honroso de la sociedad dramática calderoniana. Por lo demás, Vitse ha presentado antes el enamoramiento súbito de don Juan como ejemplo de "concordancia con el código de amor verdadero" (30) al quedar fascinado por la "divina" hermosura de Leonor. ¿Según esto, el código de amor verdadero implica violar a la mujer amada? 
pregunta si es caballero y le advierte que ella es más de lo que él parece pensar. A ambas observaciones don Juan responde contra sus obligaciones de caballero, las cuales ignora explícitamente:

LEONOR ¿Vos sois noble?

DON JUAN No lo sé.

LEONOR Mirad que soy...

DON JUAN Nada advierto.

LEONOR ... más que pensáis.

DON JUAN Poco importa. (1012)

Otro dato importante: don Juan reconoce en la mujer del aposento a la dama que previamente había atraído sus miradas (como apunta Barzoque: "pues es la mujer que está / sobre esa silla durmiendo / la misma que adoras", 1011). Y esa dama vista y amada súbitamente la había encontrado en la misa de San Jorge, y la había descrito como una deidad, hermosura superior a todas (10001001), calificándola de dama (1003), y creyendo "que una mujer como aquella / a pie no fuera muy lejos" (1002), es decir, la considera dama digna de ir en silla o coche... Todos los detalles previos conducen a pensar que la tal dama está muy lejos de ser "una mujercilla" violentable con impunidad.

Don Juan no es un fiel observante de no pocos de los preceptos de las leyes del honor. Es un gemelo -mutatis mutandis- del capitán Ataide de El alcalde de Zalamea, no de don Gutierre de El médico de su honra, con quien Vitse lo compara.

\section{¿LEONOR, HEROÍNA TRIUNFANTE?}

En lo que Leonor se refiere, Vitse la define como "eficacísima heroína del honor, activa, ingeniosa, con gran capacidad estratégica y perfecto autodominio" (33) y ofrece definir las estrategias de Leonor para alcanzar sus objetivos, oponiéndose "categóricamente" a mi definición de Leonor como víctima -no heroína triunfal-. No sé si hemos leído la misma obra. Leonor ¿heroína de admirables estrategias? ¿Cuáles? La única que queda claro en el análisis de Vitse (que comparte esta mirada con otros ilustres estudiosos como Pedraza, Antonucci...) es la estrategia del callar. Creo que Vitse se contradice al apuntar 
por un lado que el silencio es la estrategia elegida (y no impuesta), ${ }^{20} \mathrm{y}$ hablar luego de la "liberación" -momentánea- de su palabra, que en el desenlace vuelve a sepultarse en el silencio. Si la palabra equivale a la liberación ¿por qué "elige" el silencio? Vitse describe a Leonor como una hábil investigadora que consigue descubrir a su violador y recuperar el honor a través de un matrimonio, identificado una vez más -como hace Antonucci- con un final feliz. Pero a diferencia de Antonucci -que argumentaba que, puesto que Leonor perseguía el matrimonio y lo conseguía, el final es feliz $-^{21}$ Vitse, con sibilina e inaceptable sutileza, considera que es una felicidad no amorosa -pues tal cosa sería peliaguda de defender-, sino "honrosa", una variedad de dicha poco satisfactoria sin duda para la víctima de la violación. ${ }^{22}$ Pero no se trata solo del final.

Escribía yo en mi análisis anterior:

Un rasgo esencial -inexistente en No hay cosa como callar- es que los enredos de capa y espada van asociados indisolublemente al ingenio. La trama se teje con casos de azar, a los que debe responder la habilidad de los personajes, y con las actuaciones de estos, según una cadena de acción y reacción donde se despliega el ingenio de los triunfadores, tanto para crear situaciones como para solventar las dificultades que provocan los otros o los azares imprevistos. En No hay cosa como callar no se percibe este mecanismo del que procede la mayor carga cómica del género de capa y espada. $(2013,622)$

20. Pero sí le es impuesta por las convenciones sociales del honor. Escribe Vitse (39) que Leonor se halla privada de cualquier medio de acción "y condenada al silencio" (condenada, en efecto, al silencio). Esta descripción es mucho más certera que la que implica, líneas después, el apuntar que "se mostrará capaz de no revelarle nada a don Luis que concierna a la devastación de su honor", como si ese silencio fuera una hazaña heroica. Pero esto no es una estrategia ni expresa valentía alguna: ¿cómo va a proclamar su deshonra ante su prometido? No se trata de un silencio "escogido y asumido por la víctima" (Vitse 40), sino obligado por el hecho mismo de ser víctima. Que no pida reparación escandalosa y pública no puede sorprender (Vitse 40: "Con gran sorpresa de su auditor -y podemos suponer de los oyentes del teatro- no va a tratar de vengarse, es decir, de pedir reparación haciendo público el escándalo de su violación”) porque ninguna sorpresa puede causar esto en los oyentes conocedores de las convenciones, es decir, ninguna sorpresa puede esto causar a Vitse; ignoro por qué hace semejante afirmación: como se reitera en toda la obra por varios personajes, los lances de honor exigen el secreto y Leonor no puede publicar su propia deshonra.

21. Yo negaba tal felicidad pues el matrimonio no es el querido por Leonor, sino el mal menor que debe asumir resignadamente.

22. "La violentada figura de Leonor cerrará definitivamente la puerta de la felicidad amorosa", persiguiendo entonces el honor como "felicidad honrosa" (Vitse 35). 
Pues Vitse pondera las estrategias de Leonor, pero no precisa ninguna o las que precisa no son tales estrategias, sino meros casos de azar independientes de la supuesta admirable valentía, ingenio y capacidad de Leonor, que en la obra se limita a sufrir lo que viene sin que su acción modifique en nada esencial los acontecimientos. En la sinopsis anterior se percibe que cada paso adelante en la localización de su violador obedece a circunstancias azarosas, y nunca a la iniciativa de Leonor.

La venera sirve solo para que Leonor reconozca a Marcela cuando vuelca el coche de esta y la socorren en casa de aquella. En este momento Leonor toma, sí, una iniciativa: acudir a casa de Marcela, pero se ve obligada a entregar la joya a su dueña primitiva sin conseguir averiguar la identidad de su violador: la iniciativa de Leonor no consigue ningún resultado. Más adelante la venera regresa a sus manos (sin que Leonor haga nada para ello: Marcela la regala a don Diego, hermano de Leonor), ${ }^{23}$ pero sigue siendo un objeto inerte: pues en el desenlace la dama agraviada reconoce a don Juan cuando este irrumpe en su casa, huyendo de una riña en la que ha herido a un hombre (azar de nuevo). Y lo reconoce por haberlo visto la noche fatal de su violación. Dicho de otro modo: la venera es inútil a efectos de la trama y ninguna acción de Leonor consigue recuperar al galán violador.

El único recurso que Leonor puede poner en práctica es el silencio, protección de su vida y de su honor, mientras espera -angustiada y sin saber cómo encarar el problema- que alguna casualidad le revele la identidad de su agresor. De hecho, es una casualidad -el accidente de Marcela- lo que le permite dar el primer paso, averiguando la casa de la mujer del retrato. Pero acude a ver a Marcela llevando consigo la única pista (la venera), lo cual podría más bien considerarse una imprudencia, como los sucesos siguientes demuestran, al perder Leonor el objeto probatorio.

A partir de ahí nada de lo que hace (solo guardar silencio) conduce a su reparación. Será otra casualidad (la fuga de don Juan, que va a parar a casa de la dama) la que le permita por fin reconocer a su violador, sin que tal reconocimiento proceda de ninguna acción conducida por ella. En la tensa situación que se produce ni siquiera exige matrimonio: pide solo al galán, si no quiere casarse, que guarde el secreto.

23. Y Leonor la coge al verla en su casa: resulta excesivo llamar a esto "feliz actuación que le permitirá recuperar la venera" (Vitse 39): venera que por otra parte resulta un objeto sin función real en la anagnórisis. 


\section{EL DESENLACE: SECRETO A VOCES}

Don Juan, cínico y brutal, se niega, en efecto, al matrimonio. ¿Es alguna nueva invención de Leonor la que consigue al fin su mano? Nada de eso. Es una casualidad otra vez, independiente de la voluntad y las acciones de Leonor: la llegada de don Diego y don Luis, que descubren a don Juan riñendo sospechosamente con ella y exigen explicaciones, y sobre todo la llegada muy importante- del viejo don Pedro, padre de don Juan. Si recuperamos las peripecias anteriores recordaremos que don Pedro fue el garante del honor de la dama al refugiarse ella del incendio: don Juan se da cuenta de que sería muy difícil enfrentarse a los otros galanes, y sobre todo a su propio padre obligado a la defensa de la agraviada-, y cede al fin. En toda esta escena final Leonor es espectadora pasiva, que mantiene su secreto -que ya no lo es para nadie- y que recibe la mano de don Juan, a la que ya había renunciado para ir a un convento ${ }^{24}$.

Queda todavía por examinar si este desenlace, sea resultado de unas u otras circunstancias, puede calificarse de final feliz. Pero antes conviene revisar la única estrategia real de Leonor según el texto de la comedia: el silencio y el secreto impuesto por el código del honor.

La violación deshonra socialmente a Leonor y le impide casarse con don Luis. Frustrados sus deseos y esperanzas, la situación solo puede subsanarse parcialmente mediante la boda con su ofensor o la reclusión en un convento -como sucede a Isabel en El alcalde de Zalamea-, y mientras eso no sea factible, el secreto férreo, para evitar que la deshonra sea evidente y se active en el medio social.

24. Vitse: "Puede por fin liberar su palabra y sin revelar nada de su deshonra [...] obtiene un casamiento reparador" (41; énfasis mío). Obtiene casamiento reparador, pero su deshonra queda revelada, aunque en un círculo restringido que "perdona" tal deshonra porque se produce el casamiento. El supuesto secreto final en el que todos callan es más bien "diplomático": don Luis se da cuenta de lo que pasa al recordar el relato que le hizo don Juan de su aventura nocturna -con explícitos detalles que le permiten saber que fue Leonor la violada-, y los demás pueden intuir fácilmente que si un galán está riñendo con Leonor y la solución es el matrimonio, se trata sin duda de una cuestión que atañe a la honra. Por eso mismo todos deciden callar, no porque ignoran, sino porque ahora ya lo saben: si don Diego "no alcanza nada al secreto" será porque prefiere no pensar en él, aunque sabe que con lo que está sucediendo (el matrimonio concertado) "está remediado / mi honor" (entonces algo imagina); el viejo don Pedro lo ha comprendido perfectamente (1037). Todos entienden que pasa algo raro en ese matrimonio repentino y si nadie puede o quiere pedir explicaciones es porque se dan cuenta de que el tema es tabú. ¿Y qué tema tabú puede ocurrir en semejante contexto? A nadie puede quedar duda de que hay un problema de honor implicado y el silencio de todos no salvaguarda el secreto. Solo subsana, como mal menor, la violación. Se trata de un control de daños, pero no de un final feliz -ni con felicidad amorosa ni con felicidad honrosa-. 
El código del honor en los modelos trágicos no ofrece otras salidas. El secreto y el silencio que la dama se impone revela precisamente su encierro total en sí misma, la imposibilidad incluso de hacer libremente pesquisas o emprender acciones en busca de remedio -como puede doña Juana en Don Gil de las calzas verdes y otras tantas damas de capa y espada-.

Puede que No hay cosa como callar sea un caso límite, pero de tragedia, no de comedia cómica. Ninguna neutralización o desactivación de los componentes trágicos se percibe. Los que están desactivados como marca genérica son precisamente los cómicos. ${ }^{25}$

\section{OTRAS APROXIMACIONES VARIADAS DEL VOLUMEN}

Menos problemáticos se presentan otros trabajos o motivos de este libro. Santiago Fernández Mosquera da algún rodeo prescindible en "Reescritura y cambio de género en Calderón" (18-26) para concluir con acierto que la decisión genérica es primaria y que es esta decisión la que orienta la reescritura (no al revés): el título de su trabajo resulta entonces, algo desorientador: sería mejor "Cambio de género y reescritura", porque es la decisión previa genérica la que define las nuevas convenciones y rasgos de la reescritura y no la reescritura la que da lugar a un nuevo género o a un cambio de género. La pregunta “¿existe una reescritura que implique un cambio de género?" debe plantearse mejor: "¿qué supone la elección de un determinado género a la hora de reescribir una obra?". De alguna manera se retoma la cuestión en el artículo de Wolfram Aichinger ("El secreto a voces de Calderón: comedia palatina, comedia cómica, comedia de secretos", 123-41 -donde, por cierto, las convenciones genéricas permiten un uso del secreto muy diferente del de No bay cosa como callar o $A$ secreto agravio secreta venganza-), al señalar que "el ambiente de comedia palatina prefigura la selección de los nombres, el tratamiento de los personajes, el ensamblaje de episodios, la organización del tiempo [...], el papel que se asigna al azar" (124), que es otro modo de decir que la elección del género decide las convenciones estructurantes de una pieza -aunque no obliga a respetarlas absolutamente en toda obra, momento o autor-.

25. Ya he señalado en varias ocasiones que la presencia puntual de elementos cómicos no convierte a una tragedia en comedia ni siquiera en ese híbrido supuesto que suele llamarse "tragicomedia". La "auténtica comicidad" de no pocos momentos de la pieza (Vitse 42) en este asunto es irrelevante. Ver Arellano 2011b. 
Las contribuciones de Fausta Antonucci ("El segundo Cipión y la desactivación de lo trágico", 47-57), Isabel Hernando Morata ("La tragedia nueva y El principe constante de Calderón”, 59-70), Fraçoise Gilbert ("El final de El médico de su honra de Calderón: desenlace en dos tiempos, pero sin ambigüedad", 71-82), Diego Símini ("Calderón en salsa florentina: Il maggior mostro del mondo de Giacinto Andrea Cicognini”, 103-22), Natalia Fernández ("Dos maneras de hacer teatro: las versiones de El mágico prodigioso de Calderón", 165-78), Julie Botteron ("Celos de una imagen: el misterioso retrato en $\mathrm{La}$ dama duende, de Calderón”, 179-92), constituyen útiles aproximaciones a las comedias que estudian, y no plantean especiales conflictos teóricos o prácticos en la discusión sobre géneros.

El cierre del volumen corresponde a "Felipe IV con Juan Rana, de Gaspar de Crayer: un posible nuevo documento pictórico para un actor calderoniano" de Julio Vélez Sainz (193-204). No plantea propiamente cuestiones genéricas pero se trata de una revelación singular (en palabras del editor Sánchez Jiménez). Vélez compara el cuadro de Crayer con la conocida pintura identificada habitualmente con Juan Rana (enano) conservada en la Real Academia Española, y concluye que el lacayo (porque el cuadro de Crayer se titula "Retrato de Felipe IV con lacayo") podría ser Cosme Pérez (porque el lacayo es otro enano), viendo revelador parecido con la tabla de la Real Academia. Convendría usar un título algo menos asertivo, porque tal identificación tiene dos problemas no resueltos: el primero que no es seguro que la tabla de la Real Academia represente al actor Cosme Pérez ni siquiera a su máscara de Juan Rana; el segundo que según Álvarez Sellers $(300)^{26}$-citada por Julio Vélez, pero sin tener en cuenta lo que aduzco a continuación- Cosme Pérez no era enano, pues antes de ser gracioso de entremeses hizo los papeles de Leonardo y de capitán Medrano en El desdén vengado y La nueva victoria de don Gonzalo de Córdoba, ambas piezas de Lope y ambos papeles de personaje de estatura normal: "Por consiguiente su apariencia sería la de un hombre normal sin los evidentes defectos del retratado" (Álvarez Sellers). La identificación, por el momento, queda pues muy en el aire.

Resta un trabajo por mencionar. Desde el punto de vista genérico las consideraciones de Robert Folger en "Las comedias de honor y la producción

26. Álvarez Sellers (300-07) duda incluso de que el retrato habitualmente conocido como de Juan Rana sea del actor Cosme Pérez ni de la misma máscara de Rana. Podría ser un bufón cualquiera. 
del poder soberano: el caso de El médico de su honra" (83-102) suscitan alguna reflexión que afecta a la especie de los dramas de honor.

Primera cuestión: no convendría "ubicar la obra en una taxonomía genérica definida, principalmente por el contenido del drama" (83), pues los "contenidos" no pueden definir un género. Dicho de otro modo: el tema del honor no define el género "drama de honor", sino a la inversa: el tema del honor aparece con muy diferentes tratamientos, y la fuente de máxima pluralidad en las perspectivas del honor es precisamente la distinción genérica: ${ }^{27}$ hay dramas de honor que imponen un tratamiento trágico (El médico de su honra), autos sacramentales de honor (No le arriendo la ganancia, de Tirso; El primer duelo del mundo, de Bances Candamo), burlas de honor en comedias de capa y espada, entremeses y comedias burlescas, etc. ${ }^{28}$

Segunda: es probable -no podría asegurarlo- que algunas concepciones del teatro que sirven a Folger de apoyaturas, como la de Jameson ("los textos literarios son intervenciones en la historia") o Poppenberg (el teatro es "una mitología política"), etc., no resulten demasiado aclaradoras, por requerir en sí mismas toda una explicación compleja. En ese sentido la aplicación del concepto de la nuda vida de Giorgio Agamben al Médico de su honra como ejemplo de la construcción de la soberanía es muy discutible en el contexto aurisecular. El honor no está -como sostiene Folger- conectado con la idea de la limpieza de sangre -viejas ideas de Américo Castro y seguidores-, sino con la autoridad del estamento nobiliario. ${ }^{29} \mathrm{El}$ problema de don Gutierre es que como noble está obligado a mantener su estatuto honroso -consistente en la opinión o reputación- so pena de ser expulsado del sistema -fuera del cual un noble no puede sobrevivir-, pero en su caso el ofensor es un príncipe contra el cual no se puede atentar por ser figura de superior autoridad; de ahí el recurso al mismo rey, que no es capaz de preservar el honor de don Gutierre, pero que al final acepta la cura trágica que el caballero ejecuta. El drama, sin embargo, no denuncia la violencia del poder (ejecutada por Gutierre) contra la nuda vida (Mencía), pues el mismo Gutierre es otra víctima. Y la figura máxima del poder (el rey) no es en este caso el responsable directo de la catástrofe.

27. Ver Arellano 2015a; Galván 2015.

28. No es pertinente por tanto la evocación de la sociedad española del XVII como una sociedad obsesionada por el honor, ni patológicamente -esto lo niega bien negado Folger- ni tampoco como expresión de la crisis de soberanía en términos de Agamben o Carl Schmitt.

29. Hay muchas formas de deshonra; la deshonra conyugal es una de las más nítidas, pero ni mucho menos la única. 
Por otra parte, la soberanía de un rey español del Siglo de Oro -da igual que se proyecte en un monarca medieval- dista mucho de ser absoluta, al menos en la consideración de las doctrinas políticas al uso. Lejos de poder "suspender las leyes" a su gusto, el rey está sometido a un poder superior, el de la ley -sin contar el de Dios-. Como explica Quevedo en Política de Dios, el rey no puede hacer cualquier cosa; solo puede hacer lo lícito: "Solo, señor, se puede lo lícito, que lo demás no es ser poderoso, sino desapoderado" (1966, 94). La ley le impondrá las decisiones pertinentes. Coincide Quevedo con Saavedra Fajardo cuando este explica que la justicia peligraría si fuese dependiente de la opinión del príncipe y no escrita: "Por una sola letra dejó el rey de llamarse ley. Tan uno es con ella que el rey es ley que habla y la ley un rey mudo. Tan rey que dominaría sola si pudiese explicarse" (359). Dicho de otro modo: el rey es solo la voz de la ley: "Sobre las piedras de las leyes, no de la voluntad, se funda la verdadera política" (359). No es otra cosa la tiranía, afirma Saavedra Fajardo, que el desconocimiento de la ley, atribuyéndose el príncipe su autoridad (360). No es cierto, pues, que el poder resida "en última instancia en la decisión «cruel» del soberano en la cual el bios se convierte en zoe" (Folger 95). Si esto sucediera así el rey detentaría un poder ilegítimo. Claro que siempre se puede argumentar que las doctrinas que exigen la legitimación de un rey por la justicia no son sino máscaras que ocultan la verdadera cara absoluta del poder... Pero esto sería otra historia.

\section{CODA}

La definición de un género es un camino de ida y vuelta y retorno, de conceptos estructurales a los análisis de las obras concretas, contrastando y corrigiendo detalles, convenciones funcionales y aspectos de la recepción. En el enorme corpus del teatro aurisecular, y en particular en el complejo corpus del teatro calderoniano se plantean dificultades para establecer las taxonomías o sus límites, los modelos y la evolución de los mismos. En este volumen aparecen algunas de esas dificultades y se aducen algunas propuestas que se suman a la tarea crítica concerniente. Al hilo de algunas de esas propuestas, sirvan los presentes comentarios como una fase más en el camino todavía abierto para un mejor entendimiento del teatro del Siglo de Oro y del inmenso Calderón. 


\section{OBRAS CITADAS}

Álvarez Sellers, Alicia. Del texto a la iconografía: aproximación al documento teatral del siglo XVII. Valencia: Universidad de Valencia, 2008.

Antonucci, Fausta. "Riflessioni su No bay cosa como callar e sulla sua appartenenza di genere". Giornate Calderoniane Calderón 2000 (Atti del Convegno Internazionale. Palermo 14-17 Dicembre 2000). Ed. Enrica Cancelliere. Palermo: Flaccovio Editore, 2003. 159-69.

Arellano, Ignacio. "Bances Candamo, poeta áulico: teoría y práctica en el teatro cortesano del postrer Siglo de Oro”. Ibero Romania 27/28 (1988a): 42-60.

Arellano, Ignacio. "Teoría dramática y práctica teatral: sobre el teatro áulico y político de Bances Candamo”. Criticón 42 (1988b): 169-92.

Arellano, Ignacio. "Teoría y práctica de los géneros dramáticos en Bances Candamo". Teatro español del Siglo de Oro: teoría y práctica. Ed. Cristoph Strosetzki. Madrid: Iberoamericana/Frankfurt am Main: Vervuert, 1998. 1-26.

Arellano, Ignacio. Convención y recepción: estudios sobre el teatro del Siglo de Oro. Madrid: Gredos, 1999.

Arellano, Ignacio. Estructuras dramáticas y alegóricas en los autos de Calderón. Pamplona: Universidad de Navarra/Kassel: Reichenberger, 2001.

Arellano, Ignacio. "Conflictos de poder en los autos sacramentales de Calderón”. Studi Ispanici 36 (2011a): 67-85.

Arellano, Ignacio. "Lo trágico y lo cómico mezclado: de mezclas y mixturas en el teatro del Siglo de Oro". Rilce 27.1 (2011b): 9-34.

Arellano, Ignacio. "No bay cosa como callar de Calderón: honor, secreto y género". Rilce 29.3 (2013): 617-38.

Arellano, Ignacio. "Éticas del honor (y del poder) en el teatro del Siglo de Oro". Boletín de la Real Academia Española 95.311 (2015a): 17-35.

Arellano, Ignacio. "Masculinidades ansiosas en tratadistas ibéricos de conducta áulica (Siglo de Oro)”. Criticón 123 (2015b): 193-212.

Bances Candamo, Francisco Antonio. Teatro de los teatros. Ed. Duncan Moir. London: Tamesis, 1970.

Calderón de la Barca, Pedro. Obras completas, I: Comedias. Ed. Ángel Valbuena Briones. Madrid: Aguilar, 1987a.

Calderón de la Barca, Pedro. Obras completas, II: Dramas. Ed. Ángel Valbuena Briones. Madrid: Aguilar, 1987b.

Calderón de la Barca, Pedro. El nuevo palacio del Retiro. Ed. Alan G. K. Paterson. Pamplona: Universidad de Navarra/ Kassel: Reichenberger, 1998. 
De Armas, Frederick. “«En dos pechos repartidos»: Felipe IV y su valido en Cómo ba de ser el privado". Hispanófila 140 (2004): 9-20.

De Armas, Frederick. "Calderón y Virgilio: El golfo de las sirenas como égloga". Calderón frente a los géneros dramáticos. Ed. Antonio Sánchez Jiménez. Madrid: Ediciones del Orto, 2015. 143-61.

Folger, Robert. "Las comedias de honor y la producción del poder soberano: el caso de El médico de su honra". Calderón frente a los géneros dramáticos. Ed. Antonio Sánchez Jiménez. Madrid: Ediciones del Orto, 2015. 83-102.

Galván, Luis. "Educación, propaganda, resistencia: literatura y poder en teorías, tópicos y controversias de los siglos XVI y XVII". Autoridad y poder en el Siglo de Oro. Ed. I. Arellano, C. Strosetzki y E. Williamson. Pamplona: Eunsa/ Madrid: Iberoamericana/Frankfurt am Main: Vervuert, 2009. 51-87.

Galván, Luis. "El motivo del uxoricidio en la comedia española del Siglo de Oro: derecho, poder y función de la literatura". Romanische Forschungen 127.4 (2015): 482-512.

Iglesias, Rafael. "El imposible equilibrio entre el encomio cortesano y la reprimenda política: hacia una nueva interpretación de Cómo ha de ser el privado de Quevedo". La Perinola 9 (2005): 267-98.

Maravall, José Antonio. La cultura del Barroco. Barcelona: Ariel, 1980.

Moir, Duncan. "Introducción”. Francisco Antonio Bances Candamo. Teatro de los teatros. London: Tamesis, 1970.

Montaner Frutos, Alberto. "La legitimación del poder en los autos sacramentales de Calderón”. La comedia. Ed. Jean Canavaggio. Madrid: Casa de Velázquez, 1995. 397-424.

Newels, Margarete. Los géneros dramáticos en las poéticas del Siglo de Oro. London: Tamesis, 1974.

Pulido Serrano, Ignacio. "Calderón y Olivares: dependencia y antisemitismo en el barroco". Manuscrits 10 (1992): 183-213.

Quevedo, Francisco de. Política de Dios. Ed. James Crosby. Madrid: Castalia, 1966.

Quevedo, Francisco de. Mundo caduco. Ed. Javier Biurrun Lizarazu. Pamplona: Eunsa, 2000.

Quevedo, Francisco de. Obras completas en prosa, II: Grandes anales de quince días. Ed. Victoriano Roncero. Madrid: Castalia, 2005.

Quevedo, Francisco de. Teatro completo. Ed. Ignacio Arellano y Celsa C. García Valdés. Madrid: Cátedra, 2011.

Rico Ferrer, José Antonio. Los tratadistas ibéricos de conducta áulica: representa- 
ción, masculinidad y colaboración auriseculares. Vigo: Academia del Hispanismo, 2011.

Rull, Enrique. "Hacia la delimitación de una teoría político teológica en el teatro de Calderón". Calderón: Actas del Congreso Internacional sobre Calderón. Ed. Luciano García Lorenzo. Madrid: CSIC, 1983. 759-68.

Rull, Enrique. "Apuntes para un estudio sobre la función teológico política de la loa en el Siglo de Oro". Notas y estudios filológicos 2 (1985): 33-46.

Saavedra Fajardo, Diego. Empresas políticas. Ed. Sagrario López Poza. Madrid: Cátedra, 1999.

Sánchez Jiménez, Antonio, ed. Calderón frente a los géneros dramáticos. Madrid: Ediciones del Orto, 2015.

Vitse, Marc. "No hay cosa como callar, pieza límite". Calderón frente a los géneros dramáticos. Ed. Antonio Sánchez Jiménez. Madrid: Ediciones del Orto, 2015.27-43. 